\title{
COMPOSIÇÃO QUÍMICA DE ÓLEOS ESSENCIAIS DE ESPÉCIES DE Aniba E Licaria E SUAS ATIVIDADES ANTIOXIDANTE E ANTIAGREGANTE PLAQUETÁRIA
}

\author{
Joelma Moreira Alcântara, Klenicy K. de Lima Yamaguchi e Valdir F. da Veiga Junior* \\ Departamento de Química, Instituto de Ciências Exatas, Universidade Federal do Amazonas, Av. Gal. Rodrigo Otávio Jordão \\ Ramos, 3000, 69077-040 Manaus - AM, Brasil

\section{Emerson Silva Lima} \\ Faculdade de Ciências Farmacêuticas, Universidade Federal do Amazonas, Rua Alexandre Amorin, 330, 69010-300 Manaus - \\ AM, Brasil
}

Recebido em 17/3/09; aceito em 26/6/09; publicado na web em 25/11/09

\begin{abstract}
ESSENTIAL OILS COMPOSITION FROM Aniba AND Licaria SPECIES AND THEIR ANTIOXIDANT AND ANTIPLATELET ACTIVITIES. Leaves and stems from Aniba panurensis (Meisn.) Mez, Aniba rosaeodora Ducke and Licaria martiniana (Mez) Kosterm. were collected in the Reserva Florestal Adolpho Ducke-AM and their essential oils were obtained by hydrodistillation procedures. The oils were analyzed by GC-FID and GC-MS resulting on fifty and six compounds being identified. The major components were linalool in A. rosaeodora, and $\beta$-caryophyllene in A. panurensis and L. martiniana. At qualitative assays the oils showed antioxidant and antiplatelet activities, but only weak activities were found at quantitative spectrometric assays.
\end{abstract}

Keywords: Lauraceae; caryophyllene; linalool.

\section{INTRODUÇÃO}

Após séculos de exploração desordenada na Região Amazônica, as espécies da família Lauraceae produtoras de óleos essenciais continuam tendo interesse comercial, mas com poucos estudos químicos e farmacológicos. Espécies produtoras de óleos essenciais como o de pau-rosa (Aniba rosaeodora), casca preciosa (Aniba canelilla) e sassafrás (Ocotea odorifera) estão em extinção, ou próximas dela, mas ainda agregam grande valor econômico para as comunidades da região, abastecendo os mercados nacionais e internacionais de cosméticos e perfumes.

Na biodiversidade Amazônica ainda há espécies da família Lauraceae que nunca foram analisadas, entre as 400 espécies observadas no Brasil (distribuídas em 25 gêneros). ${ }^{1}$ Entre as espécies que já foram estudadas quimicamente durante as extensas pesquisas realizadas por Otto Gottlieb na década de 1970, poucas tiveram seus extratos testados em ensaios farmacológicos, em especial para as doenças que mais atingem o homem moderno.

Derivados sintéticos do safrol, encontrado principalmente nos óleos essenciais de sassafrás (Ocotea odorifera) e Ocotea quixos, possuem propriedades de antiagregação plaquetária pela inibição da cascata do ácido araquidônico e da atividade da trombina. ${ }^{2}$

Radicais livres e espécies reativas de oxigênio desempenham papel fundamental no metabolismo celular. No entanto, quando em excesso, podem gerar estresse oxidativo, levando às alterações teciduais responsáveis por diversas patologias, incluindo o câncer. ${ }^{3}$ Contudo, há vários sistemas não enzimáticos que contribuem para a inativação das reações de radicais livres, como os antioxidantes.

Em A. rosaeodora o teor de linalol varia de 74 a $96 \%$ do seu óleo essencial e no extrato etanólico foi observada a presença de cotoína. ${ }^{4,5}$ Em estudos fitoquímicos realizados com A. panurensis foram isolados 6-estiril-2-pironas e o alcaloide 6,8-didec-(1Z)-enil-5,7-dimetil-2,3di-hidro-1-H-indolizínico como o sal ácido de trifluoroacético, ${ }^{6}$ que possui atividade antifúngica contra Candida albicans. ${ }^{7}$ A espécie $L$. martiniana não possui nenhum estudo químico na literatura.

*e-mail: valdirveiga@ufam.edu.br
Este trabalho visa descrever a composição dos óleos essenciais obtidos de Aniba rosaeodora (caules) e de mais duas espécies amazônicas inéditas da família Lauraceae Aniba panurensis (folhas) e Licaria martiniana (caules e folhas), e avaliar o potencial antioxidante e a inibição de agregação plaquetária destes óleos.

\section{RESULTADOS E DISCUSSÃO}

A análise por cromatografia em fase gasosa com detectores de ionização de chama (CG-DIC) e de espectrometria de massas (CGEM) possibilitou a determinação da composição química dos óleos essenciais obtidos em percentuais de $98,8 \%$ para o caule de Aniba rosaeodora e de $100 \%$ para os demais óleos.

Cinquenta e seis componentes voláteis foram identificados com base nos seus espectros de massas, comparados com os da literatura e com espectroteca eletrônica, e em seus índices de retenção, obtidos por comparação de tempos de retenção com hidrocarbonetos lineares. O rendimento da extração dos óleos essenciais e os percentuais de cada componente, obtidos através de integração por CG-DIC, são apresentados na Tabela 1.

Os óleos essenciais do gênero Aniba foram os que apresentaram melhor rendimento - 1,3\% - entre todos os óleos obtidos. Os óleos essenciais de Licaria martiniana tiveram maior rendimento para as folhas $(0,9 \%)$ do que para os caules $(0,1 \%)$.

Os perfis químicos destes óleos revelaram uma proporção elevada de hidrocarbonetos sesquiterpênicos, minoritários apenas no óleo dos caules de $A$. rosaeodora, que apresentou a maior composição de monoterpenos $(89,4 \%)$, devido à sua alta concentração de linalol $(86,0 \%)$, valor que se aproxima do encontrado na literatura. ${ }^{4}$ No óleo essencial dos caules de $A$. rosaeodora o segundo constituinte mais abundante foi o óxido de cariofileno $(2,8 \%)$. Os demais constituintes apresentaram percentual inferior a $2 \%$.

O linalol é um monoterpeno alcoólico terciário de cadeia aberta que tem sido aplicado com sucesso como sedativo e anticonvulsivo, e que também possui propriedades acaricida, bactericida e fungicida já descritas. ${ }^{8} \mathrm{O}$ linalol possui uma larga aplicação em várias áreas do conhecimento humano, sendo necessária sua produção em quantidades sempre crescentes. Uma de suas características que influi no valor 
Tabela 1. Rendimentos e composição percentual dos óleos essenciais dos gêneros Aniba e Licaria

\begin{tabular}{|c|c|c|c|c|c|}
\hline \multirow{2}{*}{ Composição } & \multirow{2}{*}{ IR } & \multirow{2}{*}{$\begin{array}{c}A p \\
\text { folhas }\end{array}$} & \multirow{2}{*}{$\begin{array}{c}A r \\
\text { Caules }\end{array}$} & \multicolumn{2}{|c|}{$\mathrm{Lm}$} \\
\hline & & & & folhas & Caules \\
\hline 1. $\alpha$-pineno & 932 & - & - & $3,8 \pm 0,0$ & - \\
\hline 2. sabineno & 968 & - & $0,1 \pm 0,1$ & - & - \\
\hline 3. $\beta$-pineno & 974 & - & - & $3,4 \pm 0,2$ & - \\
\hline 4. $\alpha$-felandreno & 1000 & - & - & $3,6 \pm 0,3$ & $4,7 \pm 0,0$ \\
\hline 5. $p$-cimeno & 1020 & - & - & $0,7 \pm 0,0$ & $1,8 \pm 0,1$ \\
\hline 6. limoneno & 1025 & - & - & $1,2 \pm 0,3$ & - \\
\hline 7. $\beta$-felandreno & 1026 & - & - & - & $1,2 \pm 0,2$ \\
\hline 8. Z-óxido de linalol & 1064 & - & $1,3 \pm 0,1$ & - & - \\
\hline 9. E-óxido de linalol & 1081 & - & $1,5 \pm 0,0$ & - & - \\
\hline 10. linalol & 1100 & - & $86,0 \pm 0,2$ & $5,3 \pm 0,2$ & $6,5 \pm 0,1$ \\
\hline 11. $\alpha$-terpineol & 1186 & $0,7 \pm 0,0$ & $0,5 \pm 0,0$ & - & - \\
\hline 12. $n$-decanal & 1200 & - & - & - & $0,8 \pm 0,0$ \\
\hline 13. timol & 1290 & $0,3 \pm 0,4$ & - & - & $2,5 \pm 0,0$ \\
\hline 14. $\delta$-elemeno & 1336 & - & - & $0,2 \pm 0,3$ & - \\
\hline 15. $\alpha$-cubebeno & 1349 & $0,5 \pm 0,0$ & - & - & - \\
\hline 16. $\alpha$-copaeno & 1376 & $7,5 \pm 0,1$ & $0,9 \pm 0,2$ & $4,2 \pm 0,4$ & $3,3 \pm 0,1$ \\
\hline 17. $\beta$-bourboneno & 1383 & $7,0 \pm 0,3$ & - & - & - \\
\hline 18. $\beta$-elemeno & 1388 & $1,4 \pm 0,0$ & - & $1,1 \pm 0,0$ & $1,0 \pm 0,1$ \\
\hline 19. dodecanal & 1391 & $1,0 \pm 0,2$ & - & - & - \\
\hline 20. $\beta$-cariofileno & 1408 & $33,5 \pm 0,3$ & $1,0 \pm 0,1$ & $41,7 \pm 0,2$ & $21,4 \pm 0,0$ \\
\hline 21. $E$ - $\alpha$-bergamoteno & 1434 & $1,5 \pm 0,0$ & - & $2,0 \pm 0,3$ & $1,5 \pm 0,1$ \\
\hline 22. $\alpha$-guaieno & 1442 & $0,6 \pm 0,0$ & - & - & - \\
\hline 23. $\alpha$-humuleno & 1451 & $2,7 \pm 0,0$ & - & $4,8 \pm 0,2$ & $3,5 \pm 0,3$ \\
\hline 24. E- $\beta$-farneseno & 1450 & - & - & - & $0,6 \pm 0,1$ \\
\hline 25. Z-cadina-1(6),4-dieno & 1462 & - & - & $0,2 \pm 0,0$ & $0,6 \pm 0,0$ \\
\hline 26. isovalerato de linalol & 1469 & - & - & $5,9 \pm 0,2$ & $0,7 \pm 0,3$ \\
\hline 27. $\gamma$-gurjuneno & 1475 & - & - & $0,2 \pm 0,1$ & - \\
\hline 28. $\alpha$-amorfeno & 1476 & $1,8 \pm 0,2$ & $0,7 \pm 0,3$ & $1,4 \pm 0,0$ & $1,7 \pm 0,1$ \\
\hline 29. germacreno-D & 1478 & $25,4 \pm 0,4$ & - & - & - \\
\hline 30. $\beta$-selineno & 1484 & - & - & $7,9 \pm 0,2$ & $1,0 \pm 0,1$ \\
\hline 31. biciclogermacreno & 1494 & $1,6 \pm 0,0$ & - & - & - \\
\hline 32. $\alpha$-muuroleno & 1497 & $1,0 \pm 0,3$ & - & - & $1,0 \pm 0,3$ \\
\hline 33. $\beta$-bisaboleno & 1502 & - & - & $1,3 \pm 0,0$ & $2,3 \pm 0,1$ \\
\hline 34. $(E, E)$ - $\alpha$-farneseno & 1505 & - & - & $0,1 \pm 0,2$ & - \\
\hline 35. $\gamma$-cadineno & 1509 & $1,0 \pm 0,3$ & $0,9 \pm 0,0$ & $0,9 \pm 0,1$ & $5,7 \pm 0,2$ \\
\hline 36. E-calameneno & 1513 & $0,6 \pm 0,0$ & - & - & $1,4 \pm 0,2$ \\
\hline 37. $\delta$-cadineno & 1520 & $2,7 \pm 0,1$ & - & - & $1,3 \pm 0,0$ \\
\hline 38. E- $\gamma$-bisaboleno & 1535 & - & - & - & $0,8 \pm 0,3$ \\
\hline 39. E-cadina-1,4-dieno & 1537 & $0,6 \pm 0,2$ & - & - & - \\
\hline 40. elemol & 1544 & - & - & $1,2 \pm 0,0$ & $0,8 \pm 0,1$ \\
\hline 41. santalenona & 1566 & - & $0,7 \pm 0,0$ & $3,6 \pm 0,3$ & - \\
\hline 42. espatulenol & 1571 & - & - & - & $11,5 \pm 0,2$ \\
\hline 43. óxido de cariofileno & 1576 & $4,1 \pm 0,0$ & $2,8 \pm 0,1$ & $4,0 \pm 0,2$ & $1,9 \pm 0,0$ \\
\hline
\end{tabular}


Tabela 1. Continuação

\begin{tabular}{|c|c|c|c|c|c|}
\hline \multirow{2}{*}{ Composição } & \multirow{2}{*}{ IR } & \multirow{2}{*}{$\begin{array}{c}A p \\
\text { folhas }\end{array}$} & \multirow{2}{*}{$\begin{array}{c}A r \\
\text { Caules }\end{array}$} & \multicolumn{2}{|c|}{$\mathrm{Lm}$} \\
\hline & & & & folhas & Caules \\
\hline 44. viridiflorol & 1587 & $2,0 \pm 0,3$ & - & - & $1,4 \pm 0,1$ \\
\hline 45. guaiol & 1591 & $0,6 \pm 0,3$ & $0,8 \pm 0,0$ & - & - \\
\hline 46. rosifoliol & 1596 & - & - & $0,5 \pm 0,2$ & $1,4 \pm 0,1$ \\
\hline 47. epi-cedrol & 1614 & - & - & $0,4 \pm 0,0$ & $2,5 \pm 0,3$ \\
\hline 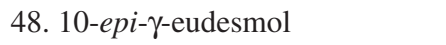 & 1622 & $0,5 \pm 0,2$ & - & - & $2,3 \pm 0,0$ \\
\hline 49. $\gamma$-eudesmol & 1629 & $0,4 \pm 0,0$ & - & - & $2,8 \pm 0,0$ \\
\hline 50. $\alpha$-cadinol & 1642 & - & $1,2 \pm 0,1$ & $0,7 \pm 0,3$ & $5,9 \pm 0,2$ \\
\hline 51. torreiol & 1646 & - & - & - & $1,2 \pm 0,1$ \\
\hline 52. 14-hidróxi-Z-cariofileno & 1657 & - & - & - & $3,2 \pm 0,1$ \\
\hline 53. n-tetradecanol & 1671 & $1,1 \pm 0,0$ & - & - & - \\
\hline 54. ni & 1695 & - & $0,7 \pm 0,0$ & - & - \\
\hline 55. ni & 1707 & - & $0,5 \pm 0,0$ & - & - \\
\hline 56. longifolol & 1709 & - & $0,6 \pm 0,0$ & - & - \\
\hline Hidrocarbonetos monoterpênicos & & - & 0,1 & 12,7 & 7,7 \\
\hline Monoterpenos oxigenados & & 1,0 & 89,3 & 11,2 & 9,7 \\
\hline Hidrocarbonetos sesquiterpênicos & & 89,3 & 3,4 & 65,8 & 47,0 \\
\hline Sesquiterpenos oxigenados & & 7,5 & 6,0 & 10,4 & 34,8 \\
\hline Outros & & 2,1 & - & - & 0,8 \\
\hline ni & & - & 1,2 & - & - \\
\hline TOTAL & & 100,0 & 100,0 & 100,0 & 100,0 \\
\hline
\end{tabular}

IR = índice de retenção, ni = não identificado, $A p=A$. panurensis, Ar = A. rosaeodora, Lm = Licaria martiniana . Nota: Os valores representam a média de 3 repetições \pm desvio padrão.

comercial dos óleos que o contém é a presença de estereocentro na sua estrutura, possuindo dois estereoisômeros: coriandrol e licareol. A quantidade destes dois isômeros influi não somente no aroma, mas também nas atividades farmacológicas.

O linalol não foi detectado no óleo essencial das folhas de $A$. panurensis, enquanto um teor máximo de $6,5 \%$ foi observado nos óleos de L. martiniana analisados. A baixa concentração, e mesmo ausência, do linalol nas outras espécies de Lauraceae estudadas ilustra e comprova um sério problema da indústria de óleos essenciais na Região Norte do país, em que espécies similares são utilizadas como sucedâneas do pau-rosa, apesar de não possuírem seu aroma.

O $\beta$-cariofileno foi o constituinte majoritário dos óleos de $A$. panurensis e L. martiniana, com concentração variando de $21,4 \%$ (caules de L. martiniana) a 41,7\% (folhas de L. martiniana). Este metabólico volátil, o mais abundante e comum entre os óleos essenciais analisados, influi em seu aroma e possui diversas atividades biológicas, tais como, anti-inflamatória, antialérgica, anestésica local, antifúngica e anticarcinogênica. ${ }^{9,10}$

No óleo essencial das folhas de A. panurensis foram detectados principalmente os hidrocarbonetos sesquiterpênicos $\beta$-cariofileno $(33,5 \%)$, germacreno-D $(25,4 \%), \alpha$-copaeno $(7,5 \%)$ e $\beta$-bourboneno $(7,1 \%)$. A somatória dos demais terpenos encontrados neste óleo equivale a menos de $10 \%$ da sua composição total.

Os principais constituintes do óleo essencial das folhas de L. martiniana foram $\beta$-cariofileno $(41,7 \%), \beta$-selineno $(7,9 \%)$, isovalerato de linalol $(5,9 \%)$ e linalol $(5,3 \%)$. O percentual de hidrocarbonetos monoterpênicos, monoterpenos oxigenados e sesquiterpenos oxigenados foram todos aproximados de $10 \%$.
No óleo essencial dos caules de L. martiniana foram detectados $\beta$-cariofileno (21,4\%), espatulenol (11,5\%), linalol (6,5\%) e $\alpha$-cadinol $(5,9 \%)$. O espatulenol, além de influir no aroma de muitos óleos de interesse comercial para a indústria de perfumes, possui propriedade antibacteriana e moderada atividade citotóxica contra células do tipo KB. ${ }^{10,11}$

O potencial da atividade antioxidante dos óleos foi determinado com base na atividade sequestrante do radical livre estável 2,2-difenil-1-picril-hidrazil (DPPH). Todos os óleos apresentaram atividade varredora de radicais livres em ensaios qualitativos, realizados em placa cromatográfica (Tabela 2). Entretanto, na análise quantitativa as concentrações ativas foram altas, sendo superiores a $700 \mu \mathrm{g} / \mathrm{mL}$.

Nenhum dos óleos essenciais analisados possui em sua composição compostos com reconhecida atividade antioxidante em quantidades significativas, tais como a presença de $\beta$-cariofileno associado com compostos fenólicos que têm seu potencial antioxidante aumentado através do efeito sinérgico. ${ }^{12}$

Os testes de agregação plaquetária demonstraram inibição inferior a 37\%, comparados ao padrão de inibição, ácido acetilsalicílico (AAS), com inibição de $100 \%$ na concentração de $0,01 \%$ (Tabela 2).

O efeito de inibição da agregação plaquetária dos óleos essenciais relatados na literatura é atribuído à presença de diferentes componentes como ácidos graxos polinsaturados e polifenóis, ${ }^{13}$ que não foram detectados nos óleos analisados. O óleo essencial dos caules de L. martiniana, que mais inibiu a agregação plaquetária $(37,0 \%)$, diferencia-se dos outros óleos pela maior percentagem de sesquiterpenos oxigenados $(34,8 \%)$. 
Tabela 2. Resultados dos ensaios das atividades antioxidante (qualitativa e quantitativa) e antiagregante plaquetária dos óleos essenciais dos gêneros Aniba e Licaria

\begin{tabular}{lcccccc}
\hline & Ap & Ar & \multicolumn{2}{c}{ Lm } & & \\
& folhas & caules & folhas & caules & AAS & Quercetina \\
\hline Antioxidante qualitativo & + & + & + & + & - & + \\
Antioxidante quantitativo $(\mu \mathrm{g} / \mathrm{mL})$ & $>1000$ & 733,0 & $>1000$ & $>1000$ & - & 3,13 \\
Inibição da agregação plaquetária $(\%)$ & 3,57 & 5,19 & 4,24 & 36,95 & 100 & - \\
\hline
\end{tabular}

Ap $=$ A. panurensis, $A r=$ A. rosaeodora, $L m=$ Licaria martiniana, AAS = ácido acetilsalicílico.

\section{PARTE EXPERIMENTAL}

\section{Material vegetal}

As folhas e caules das espécies A. panurensis (Meisn.) Mez (registro: 1276), A. rosaeodora Ducke (registro: 1473) e Licaria martiniana (Mez) Kosterm. (registro: 1890) foram coletadas na Reserva Florestal Adolpho Ducke, Manaus, Amazonas, nos meses de março de 2007 e 2008. Todo o material vegetal foi obtido de um mesmo indivíduo, na fase estéril. Todas as espécies têm exsicatas depositadas e foram identificadas no Projeto Flora da Reserva Ducke.

\section{Extração dos óleos essenciais}

As amostras de folhas e caules recém-coletados foram secas à sombra, reduzidas em moinho de facas e submetidas à hidrodestilação por um período de $4 \mathrm{~h}$, utilizando aparelho do tipo Clevenger modificado. Os óleos essenciais extraídos foram secos com sulfato de sódio anidro, acondicionados em pequenos frascos de vidro âmbar e mantidos sob refrigeração. O cálculo do rendimento foi realizado através da relação da massa do óleo obtido com a massa de material vegetal seco utilizado na extração.

\section{Análise dos óleos essenciais}

Os óleos essenciais foram diluídos em hexano e as soluções obtidas foram submetidas à análise por cromatografia em fase gasosa com detector de ionização de chama (CG-DIC) para a análise quantitativa e determinação dos índices de retenção, e por cromatografia em fase gasosa acoplada à espectrômetro de massas (CG-EM), para a obtenção dos espectros de massas. Foram realizadas três repetições para cada óleo essencial analisado.

\section{Análise em CG-DIC}

Os óleos foram diretamente analisados em cromatógrafo em fase gasosa modelo CG 2010 da Shimadzu $^{\odot}$ com detector por ionização de chama (DIC). As análises foram realizadas com coluna CP-Sil 5 CB (100\% dimetilpolissiloxano) da $\operatorname{Varian}^{\odot}$, com medidas de $15 \mathrm{~m} \mathrm{x}$ $0,25 \mathrm{~mm}$ x 0,25 $\mu \mathrm{m}$, sendo utilizado como gás de arraste hélio (He) em fluxo de $2,0 \mathrm{~mL} / \mathrm{min}$. A injeção em modo split 1:10 foi realizada com injetor a $250{ }^{\circ} \mathrm{C}$. A temperatura do detector foi de $290{ }^{\circ} \mathrm{C}$ e o forno foi programado de 60 a $180{ }^{\circ} \mathrm{C}$ a $3{ }^{\circ} \mathrm{C} / \mathrm{min}$. Foram coinjetados padrões de hidrocarbonetos lineares para a determinação dos índices de retenção.

\section{Análise em CG-EM}

Após a análise por CG-DIC, os óleos foram analisados em cromatógrafo em fase gasosa modelo QP-2010 da Shimadzu ${ }^{\odot}$ com detector por espectrometria de massas (CG-EM). As análises foram realizadas com coluna VF-1MS da $\operatorname{Varian}^{\oplus}$, com medidas de $15 \mathrm{~m}$ x $0,25 \mathrm{~mm}$ x $0,25 \mu \mathrm{m}$. As condições da análise foram as mesmas utilizadas para CG-DIC. Para a detecção foi aplicada a técnica de impacto eletrônico a $70 \mathrm{eV}$.

\section{Identificação dos constituintes dos óleos essenciais}

A determinação da composição química dos óleos essenciais foi realizada através dos dados de tempo de retenção, obtidos por CG-DIC, e dos espectros de massas, obtidos por CG-EM. Os índices de retenção foram calculados utilizando a Equação de van der DoolKratz, relacionando os tempos de retenção das substâncias presentes nos óleos essenciais com os tempos de retenção de hidrocarbonetos lineares (série homóloga de $\mathrm{C}_{9}-\mathrm{C}_{22}$ ) que foram coinjetados com a amostra. Os índices de retenção e os espectros de massas foram comparados com dados da espectroteca Wiley 7.0 e da literatura. ${ }^{14}$

\section{Análise qualitativa da atividade antioxidante}

Os óleos essenciais foram analisados por cromatografia em camada delgada (CCD) através do método de sequestro do radical livre DPPH, pela metodologia de Mensor através da capacidade sequestrante do radical estável 2,2-difenil-1-picril-hidrazil (DPPH) $0,4 \mathrm{mmol} / \mathrm{L}$ em metanol por $30 \mathrm{~s}$. As placas foram observadas até o aparecimento de manchas amarelas sob fundo de coloração púrpura, indicativo de possível atividade antioxidante. ${ }^{15}$

\section{Análise quantitativa da atividade antioxidante}

A atividade antioxidante foi avaliada por meio da capacidade sequestrante do radical estável 2,2-difenil-1-picril-hidrazil (DPPH), utilizando quercetina (Sigma-Aldrich, $\geq 98 \%$ HPLC) como padrão, expressos como valores de concentração eficiente $\left(\mathrm{CE}_{50}\right)$. Foram preparadas soluções em metanol com concentrações de 5 a $250 \mu \mathrm{g} /$ mL. O mesmo procedimento foi realizado para a solução padrão com concentrações de 0,3125 a $5 \mu \mathrm{g} / \mathrm{mL}$.

As leituras da absorbância da amostra foram realizadas após 30 min da adição da solução de DPPH $(0,3 \mathrm{mmol} / \mathrm{L})$ em espectrofotômetro UV-Vis (modelo Biomat 3 da Thermo Electron Corporation) no comprimento de onda $517 \mathrm{~nm}$, em cubeta de quartzo. Através dos valores obtidos e por regressão linear foram obtidos os valores de $\mathrm{CE}_{50}{ }^{15}$

\section{Teste de atividade antiagregante plaquetária}

O estudo da agregação plaquetária através da curva de agregação plaquetária (CAP) é um método baseado na medida da formação de agregados de plaquetas após sua exposição a um agente agregante. As medidas foram realizadas em um agregômetro (PA-04, Qualiterm, São Paulo, Brasil), basicamente um espectrofotômetro capaz de medir a variação da transmissão da luz através de uma suspensão de plaquetas, quando estas se agregam na presença de agonista. Utilizando como padrão antiagregante ácido acetilsalicílico $(0,01 \%)$ e como agregante adenosina difosfato (ADP), da Sigma $\geq 95 \%$, a $10 \mu \mathrm{mol} / \mathrm{L}$, as amostras dos óleos $(5 \mu \mathrm{L})$ foram adicionadas em $385 \mu \mathrm{L}$ de plasma rico em 
plaquetas (PRP) com concentração de aproximadamente 300.000 plaquetas por microlitro, adicionadas ao agregômetro juntamente com $10 \mu \mathrm{L}$ do agente agregante, com uma concentração final de $1 \%$. A taxa de agregação plaquetária foi monitorada por 5 min e comparada com uma amostra contendo apenas o PRP e o agente agregante. ${ }^{16}$

\section{AGRADECIMENTOS}

À FAPEAM, CAPES e ao CNPq pelo apoio financeiro e ao CBA pelo apoio técnico.

\section{REFERÊNCIAS}

1. Souza, V. C.; Botânica sistemática: guia ilustrado para identificação das famílias de Angiospermas da flora brasileira, baseado em APG II, Instituto Plantarum: São Paulo, 2005.

2. Barreiro, E. J.; Fraga, C. A. M.; Quim. Nova 1999, 22, 5; Ballabeni, V.; Tognolini, M.; Bertoni, S.; Bruni, R.; Guerrini, A.; Rueda, G. M.; Barocelli, E.; Pharm. Res. 2007, 55, 1.

3. Droge, W.; Phys. Rev. 2002, 82, 47.

4. Maia, J. G. S.; Andrade, E. H. A.; Couto, H. A. R.; Da Silva, A. C. M.; Marx, F.; Henke, C.; Quim. Nova 2007, 30, 1906.

5. Gottlieb, O. R.; Mors, W. B.; Bol. Inst. Quim. Agric. (Rio de Janeiro) 1958, 53,7 .

6. Motidome, M.; Gottlieb, O. R.; Kubitzki, K.; Acta Amaz. 1982, 12, 3.

7. Klausmeyer, P.; Chmurny, G. N.; McCloud, T. G.; Turker, K. D.; Shoemaker, R. H.; J. Nat. Prod. 2004, 67, 1732.

8. Sugawara, Y.; Hara, C.; Tamura, K.; Fujii, T.; Nakamura, R.; Masujima, T.; Aoki, T.; Anal. Chim. Acta 1998, 365, 293; Elisabetsky, E.; Brum, L.
F. S.; Souza, D. O.; Phytomedicine 1999, 6, 113; Prates, H. T.; Leite, R. C.; Craveiro, A. A.; Oliveira, A. B.; J. Braz. Chem. Soc. 1998, 9, 193; Belaiche, T.; Tantaoui-Elaraki, A.; Ibrahimy, A.; Sciences des Aliments 1995, 15,571

9. Fernandes, E. S.; Passos, G. F.; Medeiros, R.; da Cunha, F. M.; Ferreira, J.; Campos, M. M.; Pianowski, L. F.; Calixto, J. B.; Eur. J. Pharmacol. 2007, 569, 228; Passos, G. F.; Fernandes, E. S.; da Cunha, F. M.; Ferreira, J.; Pianowski, L. F.; Campos, M. M.; Calixto, J. B.; J. Ethnopharmacol. 2007, 110, 323; Ghelardini, C.; Galeotti, N.; Mannelli, L. D. C.; Mazzanti, G.; Bartolini, A.; II Farmaco 2001, 56, 387; Zheng, G. Q.; Kenny, P. M.; Lam, L. K. T.; J. Nat. Prod. 1992, 55, 7.

10. Chinou, I. B.; Roussis, V.; Perdetzoglou, D.; Loukis, A.; Planta Med. 1996, 62, 377 .

11. Pacciaroni, A. D. V.; Mongelli, H.; Espinar, L. A.; Romano, A.; Ciccia, G.; Silva, G. L.; Planta Med. 2000, 66, 720; Ulubelen, A.; Topcu, G.; Eris, C.; Sonmez, U.; Kartal, M.; Kurucu, S.; Bozok-Johansson, C.; Phytochemistry 1994, 36, 971.

12. Shahidi, F.; Wanasundara, P. K. J. P. D.; Crit. Rev. Food Sci. Nutr. 1992, 32,67 .

13. Goodnight, S. H.; Harris, W. S.; Connor, W. E.; Illingworth, D. R.; 1982, 2, 87; Correa, J. A. G.; López-Villodrez, J. A.; Asensi, R.; Espartero, J. L.; Rodríguez-Gutiérez, G.; De La Cruz, J. P.; Br. J. Nutr. 2009, 101, 8.

14. Adams, R. P.; Identification of essential oil components by gas chromatography/ quadrupole mass spectroscopy, Allured: Card Stream I L, 2001.

15. Mensor, L. L.; Menezes, F. S.; Leitão, G. G.; Reis, A. S.; Santos, T. C.; Coube, C. S.; Leitão, S. G.; Phytother. Res. 2001, 15, 127.

16. Lewis, S. M.; Hematologia prática de Dacie e Lewis, Artmed: Porto Alegre, 2006. 